\title{
The Role of Legislation, Regulatory Initiatives and Guidelines on the Control of Plastic Pollution
}

\author{
João Pinto da Costa ${ }^{1 *}$, Catherine Mouneyrac ${ }^{2}$, Mónica Costa ${ }^{3}$, Armando C. Duarte ${ }^{1}$ and \\ Teresa Rocha-Santos ${ }^{1}$ \\ ${ }^{1}$ Department of Chemistry and CESAM, University of Aveiro, Aveiro, Portugal, ${ }^{2}$ Mer Molécules Sante, Université Catholique \\ de l'Ouest, Angers, France, ${ }^{3}$ Laboratory of Ecology and Management of Coastal and Estuarine Ecosystems, Department \\ of Oceanography, Federal University of Pernambuco, Recife, Brazil
}

\section{OPEN ACCESS}

Edited by:

João P. G. L. Frias,

Galway-Mayo Institute of Technology,

Ireland

Reviewed by:

Francois Galgani, Institut Français de Recherche pour l'Exploitation de la Mer (IFREMER),

France

Ítalo Braga Castro,

Federal University of São Paulo, Brazil

*Correspondence:

João Pinto da Costa

jpintocosta@ua.pt;

joao.pinto.da.costa@gmail.com

Specialty section

This article was submitted to

Toxicology, Pollution and the

Environment,

a section of the journal

Frontiers in Environmental Science

Received: 10 May 2020

Accepted: 15 June 2020

Published: 24 July 2020

Citation:

da Costa JP, Mouneyrac C,

Costa M, Duarte AC and

Rocha-Santos T (2020) The Role of Legislation, Regulatory Initiatives and Guidelines on the Control

of Plastic Pollution.

Front. Environ. Sci. 8:104.

doi: 10.3389/fenvs.2020.00104
There has been an exponential interest in the occurrence and potential ecotoxicological consequences stemming from the growing prevalence of (micro)plastics in the environment. This has been especially evident by the increasing concern regarding the visible effects on marine ecosystems, with multiple local, regional, and transnational initiatives developed toward the mitigation of what has been construed as an environmental disaster. However, it is not clear what the benefits - if any - of the multitude of norms, regulations, laws and recommendations that have been proposed and/or implemented in recent years are. Furthermore, many of the proposed laws may be of limited applicability, particularly considering the extent to which plastic occurs in everyday life. Herein, the current regulatory instruments are overviewed, focusing on the existing proposals and the extent to which these are based on the currently available scientific data, as well as the foreseen challenges that may restrain the relevancy and suitability of such legislative proposals.

Keywords: legislation, pollution, plastics, policy, microplastics

\begin{abstract}
Abbreviations: ABNJ, Areas Beyond National Jurisdiction; ASEAN, Association of Southeast Asian Nations; CBD, Convention on Biological Diversity; CCAMLR, Commission for the Conservation of Antarctic Marine Resources; COBSEA, Coordinating Body on the Seas of East Asia; ECHA, European Chemicals Agency; FAO, Food and Agriculture Organization; GEF, Global Environment Facility; GES, Good Environmental Status; GPA, Global Program of Action; GPML, Global Partnership of Marine Litter; HELCOM, Helsinki Convention on the Protection of the Marine Environment of the Baltic Sea Area; IOC, International Oceanographic Commission; MARPOL, Convention for the Prevention of Pollution from Ships; MDP, Marine Debris Program; MPPRCA, Marine Plastic Pollution Research and Control Act; MSFD, Marine Strategy Framework Directive, or Directive 2008/56/EC; NGOs, non-governmental organizations; NMDMP, National Marine Debris Monitoring Program; NOAA, National Oceanic and Atmospheric Administration; NOWPAP, Action Plan for the Protection, Management and Development of the Marine and Coastal Environment of the Northwest Pacific Region; OSPAR, Convention for the Protection of the Marine Environment of the North-East Atlantic; PACOL, Pacific Ocean Pollution Prevention Program; PAME, Protection of the Arctic Marine Environment; PEMSEA, Partnership in Environmental Management for the Seas of East Asia; PRF, Port Reception Facility; RAPMaLi, Regional Action Plan on Marine Litter Management; REACH, Registration, Evaluation, Authorization and Restriction of Chemicals; ROPME, Regional Organization for the Protection of the Marine Environment (Persian Gulf and the Gulf of Oman); RSC, Regional seas conventions; SAICM, Strategic Approach to International Chemicals Management; SAPEA, Science Advice for Policy by European Academies; SEC, U.S. Securities and Exchange Commission; SPREP, Secretariat of the Pacific Regional Environment Program; UNCLOS, United Nations Convention on the Law of the Sea; UNEP, United Nations Environment Program; UNEP-CAR/RCU, UNEP's Program-Caribbean Regional Coordinating Unit; WHO, World Health Organization.
\end{abstract}




\section{INTRODUCTION}

Perhaps one of the most characteristic features of the proposed Anthropocene epoch is the marked increase of the influence of human activity on Earth since the 1950's (Lewis and Maslin, 2015), reflected, among others, by the beginning of the largescale manufacture of plastics. The production of these materials has undergone a steady exponential increase in past decades, as highlighted in Figure 1, growing from 15 million tons in the early 1960s to approximately 359 million tons in 2018 (PlasticsEurope, 2019), while its production is expected to triple by 2050 (WEF, 2016).

The prevalence of these materials, across an ever-expanding number of industrial sectors, has led to its accumulation in the environment, and, particularly, in Oceans, where it accounts for about $80 \%$ of all marine litter (Ryan et al., 2009). The current global pervasiveness and environmental consequences both known and unknown - of plastics material appear to be drawing an increasing level of interest by scientists, the general public and policy makers. Propelled by the growing number of news reports detailing the visible consequences to marine life, fueled by the immediacy of social networks and popular documentary TV shows, the public concern over the effects of plastics in the oceans has led to the implementation of strict guidelines and policies, although the efficacy of said regulations remains undetermined and no convention focused solely on solving the problem of marine plastic pollution exists, as well as no unified and integrated mechanisms to regulate and control the spread of these materials. Considering that some plastics are classified as carcinogenic and/or mutagenic, including polyacrylonitriles, polyurethanes, polyvinyl chloride (PVC) and epoxy resins (Lithner et al., 2011), and that plastic-associated chemicals have also been shown to be hazardous (Groh et al., 2019), there is the need to create and implement legislation aimed at curtailing, and, ideally, eliminating, the continual growing threats of plastic waste. Hence, these existing regulatory instruments and initiatives, voluntary or legally binding, are overviewed, and the inherent limitations of these, as well as the approaches to overcome such potential restraints, are discussed.

\section{INTERNATIONAL REGULATORY INSTRUMENTS AND INITIATIVES}

The United Nations Convention on the Law of the Sea (UNCLOS) of 1982, entered into force in 1994, and commonly referred to as a "Constitution for the Oceans" (Gagain, 2012), constituted an unprecedented attempt at regulating "all aspects of the resources of the sea and uses of the ocean, and thus bring a stable order to mankind's very source of life" (United Nations, 1982). Focusing on a wide range of topics, including navigational rights, territorial sea limits, economic jurisdiction, legal status of resources on the seabed beyond the limits of national jurisdiction, conservation and management of living marine resources, protection of the marine environment, a marine research regime and a binding procedure for settlement of disputes between States, it did not contain any provisions regarding plastic pollution specifically, but rather considered plastic as all other wastes potentially hazardous for the marine environment. UNCLOS is composed of 320 articles, of which 46 (Articles 192237, Part XII) cover the protection and preservation of the marine environment. For example, Article 210 obliges states to develop frameworks to "prevent, reduce and control pollution of the marine environment by dumping," while simultaneously stating that any signatory State "has the right to permit, regulate and control such dumping after due consideration of the matter with other States which by reason of their geographical situation may be adversely affected thereby" (United Nations, 1982). Hence, because ocean pollution is a transnational issue unrestrained by boundaries and the sources of marine waste, in general, and

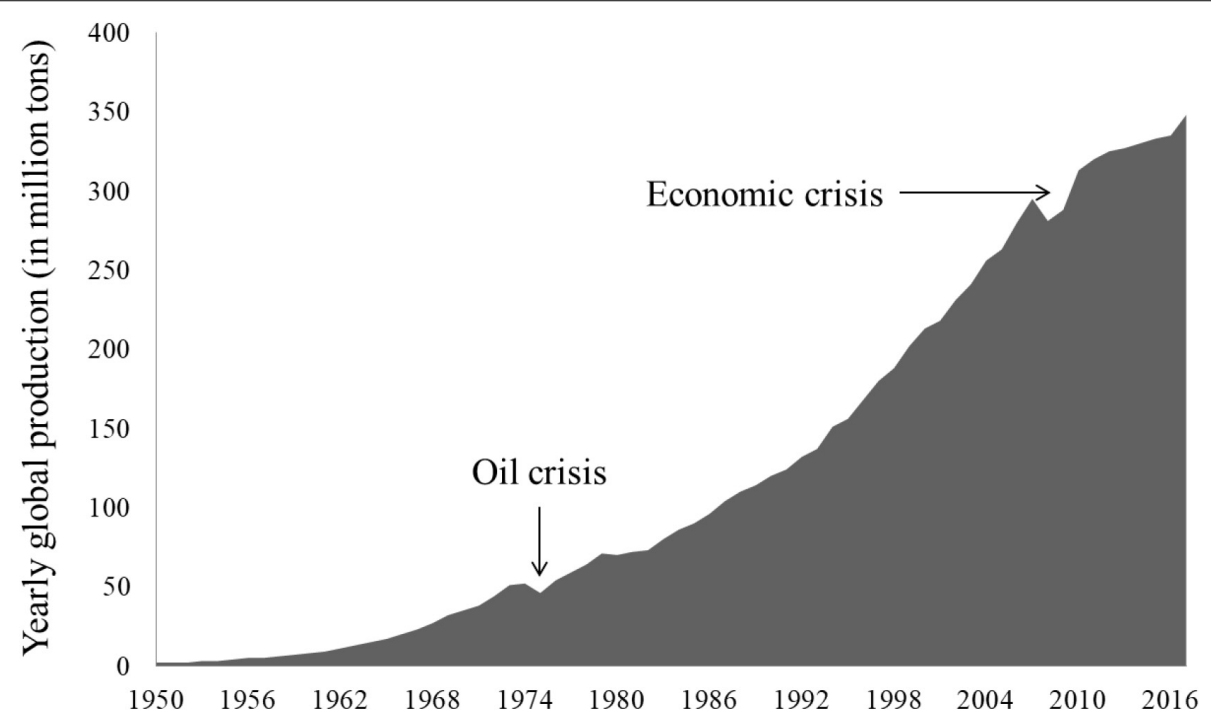

FIGURE 1 | The yearly global production of plastics, from 1950 to 2017 . Adapted from Schlanger (2018). 
plastic debris, in particular, are often difficult to identify, the measures envisioned by UNCLOS to address the problem of plastic pollution in the ocean seem to be ineffective. Additionally, this rather large and complex document has inherent limitations that mostly stem from basic regional, historic and economic conflicts. Moreover, the United States, a key player in the regional maritime security and environmental protection, is not a signatory state (Bateman, 2007). Non-compliance with the norms and principles of this Convention is somewhat recurrent, and flag states frequently do not fulfill their responsibilities. This sometimes arises from grievances caused by, among others, the added responsibilities by coastal states used for international navigation in, for example, pollution prevention, as well as search and rescue or navigational information and infrastructures, for which UNCLOS makes no provision for compensation. Yet, UNCLOS remains an important landmark and constitutes a de facto basis for communication between member states and to initiate processes that, in the long run, may actively contribute to reducing plastic litter entering the environment, depending on the will of member states. Specifically devised toward the prevention, reduction and management of marine debris, the United Nations Environment Program (UNEP) and the Marine Debris Program (MDP) of the U.S. National Oceanic and Atmospheric Administration (NOAA) have jointly developed a global agenda within the last decade. The document includes possible actions aiming at combating the increasing prevalence of marine litter, focusing on "preventing, reducing and abating the ecological, human health and economic impacts of marine debris worldwide" (UNEP/NOAA, 2011). Its application, however, is restricted to the will of participating nations, owing to its non-binding nature to meet the recognized challenge of plastic pollution. Similarly developed for dealing with oceanbased litter pollution, the Convention for the Prevention of Pollution from Ships (MARPOL), (73/78) Annex V, revised in 2012, under the International Maritime Organization, is another key international regulatory instrument (IMO, 1988). This convention requires that all ships to dispose of the generated waste at land based wasted facilities (Vince and Hardesty, 2018), and, as of mid-2016, over 154 states have ratified MARPOL, effectively accounting for approximately $99 \%$ of the global annual shipping tonnage. Complimentarily to MARPOL, guidelines have also been devised on the surveying and monitoring of marine litter and on lost, abandoned or discarded fishing gear by the International Oceanographic Commission (IOC) and the Food and Agriculture Organization (FAO) (Crawford and Quinn, 2017). Although flag states - i.e., the jurisdiction under which laws the vessel is registered or licensed, considered as the nationality of the vessel - possess the authority to enforce marine pollution restrictions and prohibitions in international waters, they often lack the resources and/or the will to fulfill their duty (Dewey, 2018). However, it is possible that multinational agreements, such as Free Trade Agreements, could enhance MARPOL compliance (Huang and $\mathrm{Hu}, 2018$ ), by playing a key role on trade, investment and dispute resolution. More recently, the United Nations Environment Assembly of UNEP gathered in Nairobi (Kenya), and passed a draft resolution on marine litter and microplastics (UNEP, 2017), i.e., plastic particles $<5 \mathrm{~mm}$
(NOAA, 2015) that can be either directly discharged into the environment, in the form of, for example, pellets or ingredients of numerous cleaning or hygiene products, or formed once in the environment, by fragmentation of larger particles (da Costa et al., 2017). Broadly, this draft document reflects the recognition that there are multiple "challenges (...) addressing marine plastic pollution in the face of increasing production and consumption of plastic in products and packaging." It also urges "all countries and other stakeholders to make responsible use of plastic while endeavoring to reduce unnecessary plastic use, and to promote research and application of environmentally sound alternatives." It is also underlined that both public and private initiatives aimed at curbing pollution are of vital importance, and, in fact, some cross industry agreements have been reached and some companies have also independently have developed efforts in this direction. These include, for example, the agreement for "the prevention of microplastic release into the aquatic environment during the washing of synthetic textiles," proposed by a group of European industry associations representing a collective membership of approximately 180.000 companies (AISE et al., 2017). Individually, some companies are also taking strides toward more environmentally friendly practices, by phasing out single-use plastics, or by cutting down the use of plastic in their products and actively replacing these with refillable recipients (Beament, 2018; Butler, 2018; Eschener, 2019). In the same year (2017), the United Nations proclaimed a Decade of Ocean Science for Sustainable Development, to be held from 2021 to 2030 (United Nations, 2020). The goal of this initiative is broader than the subjects of pollution and plastic litter, focusing on creating and fostering active science-policy interfaces, aimed at facilitating and encouraging the sustainable management of oceans and coastal areas (United Nations, 1982). Whilst still in its preparatory phase (2018-2020), this initiative may greatly benefit from the current increasing goodwill toward the protection of oceans, and the development of science-based policies stemming from multiple, integrated areas of research - physical, geological and chemical sciences, as well as marine biology - may constitute an unique opportunity in ocean conservation.

The Group of 7 (G7) and Group of 20 (G20) have also addressed the issue of marine plastic pollution. From these two groups, action plans have been devised (G20, 2017; G7, 2018). Although the declarations, by the members of these groups, stress the need to develop strategies that promote waste prevention, resource efficiency, sustainable waste management and raising awareness, most of the actions carried out have been, so far, in the form of workshops, organized by the country under which the presidency is and that have served the purpose of highlighting the need to identify better solutions to the issue of marine litter.

\section{REGIONAL REGULATORY INSTRUMENTS AND INITIATIVES}

As of June 2019, the European Union (EU) has in force the Directive on the reduction of the impact of certain plastic products on the environment (EuropeanParliament, 2019a), which requires all member states "to ensure environmentally 
sound waste management to prevent and reduce marine litter from both sea and land sources." Different strategies are envisioned for the numerous plastics used, including market restrictions and consumption reduction, ultimately leading to the promotion toward the gradual transition to a circular economy of plastics (EuropeanParliament, 2018), through the development and implementation of innovative and sustainable business models, materials and products. However, perhaps the most relevant EU directive relating to marine pollution and debris is the Marine Strategy Framework Directive (MSFD), or Directive 2008/56/EC (EuropeanParliament, 2008), which is an integrated policy aiming at achieving Good Environmental Status (GES) of the European marine environment by 2020. Briefly, the goal of the MSFD is to protect the "resource base upon which marinerelated economic and social activities depend" with the specific and explicit regulatory objective of maintaining biodiversity as the cornerstone of such goals. Therefore, the MSFD considers 11 descriptors to define GES, of which marine litter, namely, microplastics (Gago et al., 2016), is included. Furthermore, the GES of all aquatic ecosystems within the European Union are covered by the Directive 2000/60/EC, commonly referred to as Water Framework Directive (EuropeanParliament, 2000b), which has a direct impact over marine litter pollution owing to the fact that it encompasses both coastal waters and estuaries up to one nautical mile from mainland. However, despite the formal definition of GES - "The environmental status of marine waters where these provide ecologically diverse and dynamic oceans and seas which are clean, healthy and productive" - member-states may interpret what GES means in practice, although the EU has made efforts to set out eleven qualitative descriptors describing the environment when GES has been achieved. Moreover, in a subsequent Communication (EuropeanParliament, 2017), the EU added, revised and defined criteria and methodological standards for some of the qualitative descriptors detailed in the MFSD. Nonetheless, the language continues to allow different interpretations, and, therefore, this allows for some discrepancies between the used definitions by member-states. Attendant to MARPOL's Annex V, the EU has put forth specific laws aimed at curtailing and enforcing the adequate disposal of ship-generated litter, known as the Port Reception Facility (PRF) (2000/59/EC) (EuropeanParliament, 2000a), based on the "polluter pays" principle. There has also been a marked effort by the EU in the last 25 years in the development and enactment of regulations devoted to the harmonization of measures regarding the management of packaging and packaging waste, in order to "prevent any impact thereof on the environment and (...) [to] ensure the functioning of the internal market" (Directive 94/62/EC) (EuropeanParliament, 2004). However, both the MFSD and the PRF are not without limitations. In the case of the former, for example, it has been noted that EU countries have been responsible for the development of the required tools to implement the devised marine strategies, which may lead to difficulties when comparing the assessments performed by different member-states (Bellas, 2014). Recent proposed changes to the PRF have also led to some concerns as well. For example, a new policy leading to the introduction of a $100 \%$ fixed fee (indirect fee) for garbage, as well as for passively collected waste in fishing nets, may lead to the delivery of vast quantities of garbage, including dangerous waste, for a fixed fee. As some have noted (ESPO, 2018), this would constitute a severe divergence from the "polluter pays" principle. Nonetheless, presently, this provision is in force: "no direct fee shall be charged for such waste, in order to ensure a right of delivery without any additional charges based on the volume of waste (. . .); passively fished waste shall be covered by this regime" (EuropeanParliament, 2019b). Similarly, the Convention for the Protection of the Marine Environment of the North-East Atlantic - OSPAR - is a statutory mechanism signed and ratified by the EU and 15 governments intended to promote the cooperation toward the protection of the marine environment. Stemming from this collaborative initiative, specific guidelines for monitoring marine litter on beaches have been devised, which include not only practical advices, but photographic guides and standardized methodologies for the quantification and identification of the sampled litter (OSPAR, 2010). Within the OSPAR Convention, a series of Annexes for specific areas are contained, included for the Prevention and elimination of pollution from land-based sources (Annex I), Prevention and elimination of pollution by dumping or incineration (Annex II), Prevention and elimination of pollution from offshore sources (Annex III), Assessment of the quality of the marine environment (Annex IV), and On the protection and conservation of the ecosystems and biological diversity of the maritime area (Annex V). In the Southern hemisphere, and, more precisely, in Antarctica, the Commission for the Conservation of Antarctic Marine Resources (CCAMLR) was established in 1982 with the patronage of the Fisheries and Aquaculture Department of the Food and Agriculture Organization of the United Nations, 2013 (FAO, 2013). This Convention develops sets of conservation procedures that determine the use of aquatic living resources in the Antarctic, and, given the reported presence and apparent accumulation of microplastics in the Antarctic region (Waller et al., 2017), measures designed to curtail the amount of debris entering this system and to mitigate their impact in the Convention Area have been formulated (CAMLR, 2018). UNEP's regional seas conventions (RSC), launched in 1974, are perhaps the most comprehensive efforts toward the protection of coastal and marine environments, encompassing 18 regions of the World - Antarctic, Arctic, Baltic, Black Sea, Caspian, Eastern Africa, East Asian Seas, Mediterranean, NorthEast Atlantic, North-East Pacific, Northwest Pacific, Pacific, Red Sea and Gulf of Aden, Persian Gulf, South Asian Seas, South-East Pacific, Western Africa and Wider Caribbean. These programs which include UNEP and non-UNEP-administered initiatives engage neighboring countries in comprehensive and specific actions aimed at protecting their common marine environment, through a "shared seas" approach (Neretin, 2018). It comprises a multi-sectorial approach to coastal and marine areas, as well as associated environmental problems, and aims at including governments since the design and inception of the programs, as these states are, ultimately, those that mostly benefit from the implementation of such strategies (Campbell et al., 2017).

Also as a part of UNEP's Regional Seas Program, an Action Plan for the Protection, Management and Development of the Marine and Coastal Environment of the Northwest Pacific Region 
(NOWPAP) was adopted by Japan, China, the Republic of Korea, and the Russian Federation in September 1994. The mediumterm strategy (2018-2023) envisioned in NOWPAP includes the protection of biodiversity and the active monitoring of marine pollutants, namely, plastic debris (Kim, 2015).

The Wider Caribbean Region is also covered by the Regional Action Plan on Marine Litter Management (RAPMaLi), an initiative conducted by UNEP's Program-Caribbean Regional Coordinating Unit (UNEP-CAR/RCU) with financial support from the Regional Seas Program and the Global Program of Action from UNEP. Reports produced under the RAPMaLi have mostly focused on the need to continuously develop efforts in the education and awareness of the "public, government, NGOs and community groups," encouraging "persons to dispose of waste properly and address the issues of illegal dumping on abandoned beaches and gullies" (Corbin et al., 2014). This action plan also focuses on Small Islands Developing States (SIDS), increasingly more intently engaged in marine pollution issues, owing to the fact that waste disposal infrastructures and resources are limited and inadequate in many of these countries (Vince and Hardesty, 2018). Under the Secretariat of the Pacific Regional Environment Program (SPREP), the Pacific Ocean Pollution Prevention Program (PACOL) Strategy and Work Plans have been developed aimed at a "Cleaner Pacific 2025." This comprehensive blueprint details the waste and pollution management priorities of the region, focusing on the "strengthening [of the] institutional capacity, promotion of public-private partnerships, implementation of sustainable best practices, development of human capacity, dissemination of outcomes and experiences, and promotion of regional and national cooperation" (SREP, 2016). Ideally, the outcomes of the devised strategies and work plans will contribute to reducing and preventing the generation of wastes and pollution in the region, while simultaneously allowing for the recovery of resources.

Mostly centered in the Persian Gulf and the Gulf of Oman, the Regional Organization for the Protection of the Marine Environment (ROPME), formerly known as Kuwait Action Plan, is comprised of legal instrument binding the signatories Bahrain, Iran, Iraq, Kuwait, Oman, Qatar, Saudi Arabia, and the United Arab Emirates - "to coordinate their activities toward the protection of their common marine environment" (ROPME, 1979). Presently, under the framework of this convention, a protocol concerning the conservation of the biological diversity and the establishment of protected areas is being prepared.

For the East Asian region there are also numerous agreements, projects, and actors, and different action plans are in development. These are under the purview of multiple partnerships and strategies, such as the East Asian Seas Action Plan, the Sustainable Development Strategy for the Seas of East Asia, UN's Global Environment Facility (GEF) International Waters projects, the Coordinating Body on the Seas of East Asia (COBSEA), the Association of Southeast Asian Nations (ASEAN) and the Partnership in Environmental Management for the Seas of East Asia (PEMSEA). Although the initial purposes of these collaborations were mostly focused on the acceleration of both economic growth and social progress, as well as the regional cultural development in through joint endeavors, these have since included international efforts toward arresting the environmental degradation in the region of the Seas of East Asia, with tangible benefits to the environment and to the local inhabitants. At the moment, the East Asian Seas Action Plan is "geared toward cooperation with nongovernment and government organizations," as well as with the private sector to achieve the goals of a pragmatic "management, conservation, restoration and sustainable use" of the regional marine environment (UNEP-GPA, 2018).

The Baltic Sea is governed by the Helsinki Convention on the Protection of the Marine Environment of the Baltic Sea Area (HELCOM), signed in 1992. Entered into force in 2000, HELCOM's main goals are the prevention and elimination of pollution, for the ecological restoration of the Baltic Sea, the promotion of the use of Best Environmental Practice and Best Available Technology and to apply the polluter-pays principle. Additionally, the Convention clearly states that its implementation should not cause transboundary pollution outside the Baltic Sea Area (Ehlers, 1993). Under the umbrella of HELCOM, numerous guidelines have been made publicly available on wide range of topics, including for the periodical compilation and reporting of waterborne pollution inputs and monitoring of radioactive substances, to the determination of "heavy metals" in sediments and reprotoxic substances (i.e., substances that may induce reproductive toxicity) (HELCOM, 2019).

The global coverage of these regional action plans on marine litter is summarized in Figure 2. RSC and Action Plans are essential for supporting the overall implementation of the Global Program of Action, or GPA, at the national/regional levels. Although the action plans usually consist of identical approaches, each has been devised by the participating governments and local organizations and, therefore, should theoretically reflect their regional, specific environmental challenges, although, consequently, their strategies may vary in scope, legal structure and effectiveness. As noted, some countries are active participants in different action plans, which may be legally binding or merely suggestive of the best practices aimed at curtailing the prevalence of marine litter, and, specifically, plastic debris. However, the described regional plans do not constitute an exhaustive list of the currently implemented programs, although they are certainly illustrative of the existing initiatives and the extent to which multi-national efforts have been put forth toward achieving GES throughout the multiple regions of the world. In Table 1, additional regional regulatory instruments and conventions are listed, as well as a brief description of their goals and mechanisms of action.

From the previous paragraphs, it becomes clear that there are numerous regulations, recommendations and laws pertaining to pollution in the Ocean and its regulation. However, for most of these international and regional laws, conventions, agreements and regulations, the main issue remains compliance, particularly in Areas Beyond National Jurisdiction (ABNJ) (Vasilevskaia, 2018; Vince and Hardesty, 2018). ABNJ comprise over 40 percent of Earth's surface, making up 64 percent of oceanic surface and constitute approximately 95 percent of its volume (Kimball, 2005). In these areas, commonly 


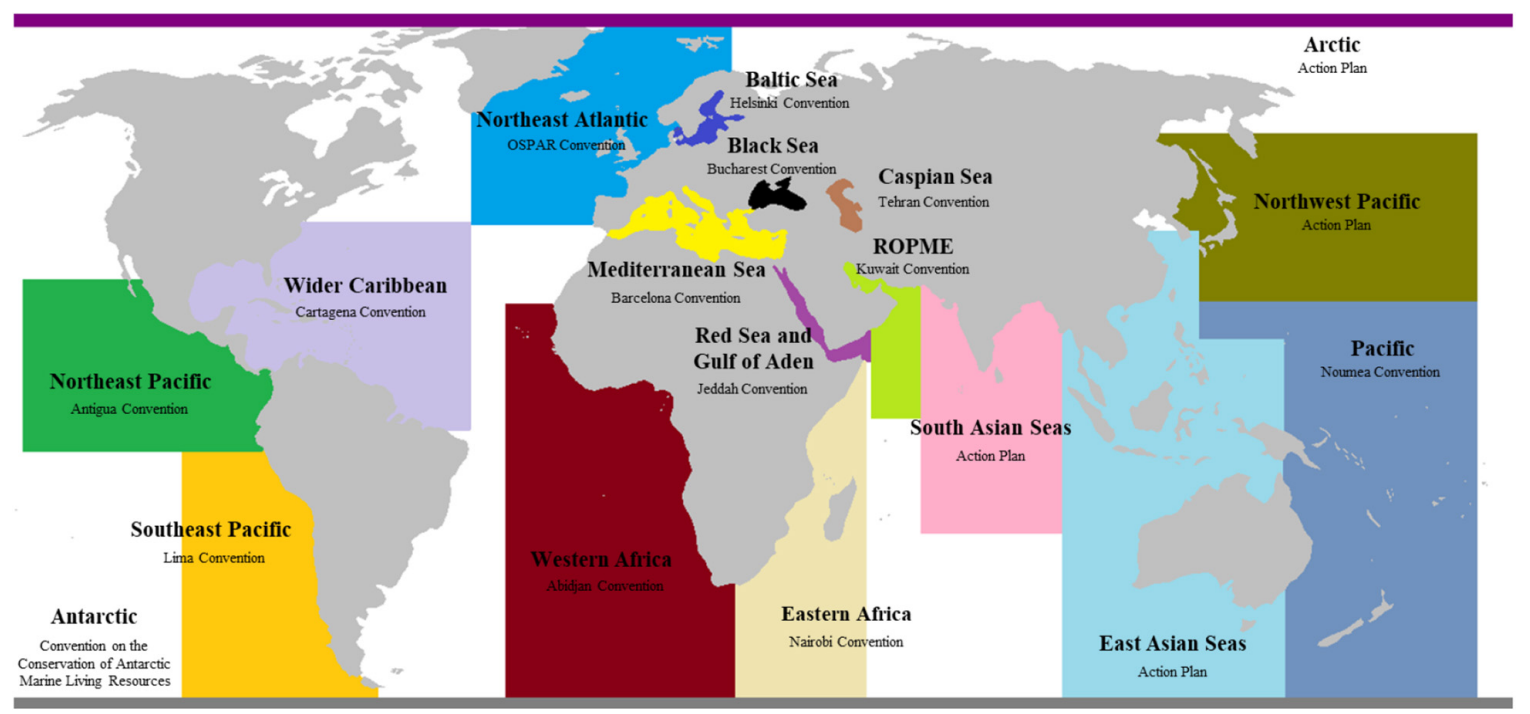

FIGURE 2 | Regional action plans on marine litter. These may vary in the aspects and extent of actions suggested to the states. For example, regional action plans in the Mediterranean include legally binding measures, while, for the Baltic and North Atlantic, these plans are based on sets of essential principles.

dubbed "high seas," no sole nation has the responsibility for its policing, monitoring and management. Consequently, fragmented legal frameworks result in increased vulnerability in these regions. Although UNCLOS encompasses an international legal regime that governs the ocean, it does not effectively aiming at the conservation of the marine environment, it does not include nor describe the specific mechanisms or instruments through which this can be achieved in ABNJ. On the other hand, regional approaches are also insufficient to address this issue, owing to the immense interconnectivity of marine ecosystems, including ocean currents and long migratory pathways. Presently, negotiations are underway to create an "Implementing Agreement" to UNCLOS. If implemented, this agreement could help closing the existing ABNJ governance gaps, providing a tool toward the conservation and sustainable biodiversity in these areas, including environmental impact assessment and pollution prevention (Gjerde et al., 2013). Strengthening cooperation and coordination, as well as regional capacities and the inter-regional cooperation are essential and promising stepping-stones for a successful ecosystem based management approach at a regional scale, including in $\mathrm{ABNJ}$ (Rochette et al., 2014). Nonetheless, international and regional accords and regulations should be supported by effective measures implemented at the national level, as these constitute key catalysts for the development of more aware and participating societies in combating pollution.

\section{NATIONAL REGULATORY INSTRUMENTS AND INITIATIVES}

At the national level, numerous governments have created legislation focusing on litter, and, particularly, on marine pollution. For example, in the United Kingdom, the Scottish legislature put forth the Marine Litter and the National Litter Strategies, in response to the EU's MSFD (Chen, 2015). To be implemented until 2020, the main goals of these legal instruments are to reduce or - ideally - prevent the incidence of litter through an outreach approach to their citizens, educating them to the dangers posed by these debris, especially within aquatic systems. Furthermore, these goals are set to be achieved by developing both tools and infrastructures, as well as deterrence and enforcement mechanisms (ScottishGovernment, 2013). Concomitantly, the United Kingdom has also developed legislation specifically targeting microplastics (Tagg and Labrenz, 2018), although not yet been subject to a vote (O'Halloran, 2017). In Canada, following the report of up to the significant presence of microbeads in Lakes Eerie and Ontario (Vermaire et al., 2017), the federal government announced its intent to add these materials to its list of toxic substances and declared a ban on the sale, import and production of personal care products containing microplastics (Pettipas et al., 2016). The US has also developed several legal instruments focused on marine litter, namely, the MDP, the Marine Plastic Pollution Research and Control Act (MPPRCA), the National Marine Debris Monitoring Program (NMDMP), the Beaches Environmental Assessment and Coastal Health and Shore Protection Acts (Crawford and Quinn, 2017). Taken together, these consist of multi-disciplinary approaches that aimed at the conservation of the marine and coastal environments, but that also take into consideration public health and human safety, as well as the economy. Federally, the Microbead-Free Waters Act of 2014 has been implemented since mid-2017, with respect to manufacturing, and, as of July 2018, it has been enforced on the introduction into interstate commerce (USCongress, 2015). The Australian government has drafted a proposal aiming at the severe mitigation of marine debris at associated impacts. The document, issued by the Australian Department of the 
TABLE 1 | Additional regional treaties, agreements and conventions for the management of marine litter and pollution.

\begin{tabular}{|c|c|}
\hline Accord & Brief description \\
\hline $\begin{array}{l}\text { London Convention on the Prevention } \\
\text { of Marine Pollution by Dumping of } \\
\text { Wastes and Other Matter }\end{array}$ & $\begin{array}{l}\text { In force since 1975, the main objective is to promote control over all sources of marine pollution, whilst simultaneously } \\
\text { taking practicable steps to prevent sea pollution. At present, } 87 \text { States are Parties to this Convention, which predicts } \\
\text { regional cooperation based on mechanisms of action that allow for the full and open exchange of information (IMO, 1996). }\end{array}$ \\
\hline $\begin{array}{l}\text { Protection of the Arctic Marine } \\
\text { Environment (PAME) Working Group }\end{array}$ & $\begin{array}{l}\text { First established under the } 1991 \text { Arctic Environmental Protection Strategy, it was continued by the } 1996 \text { Ottawa Charter } \\
\text { that established the Arctic Council. It is currently developing a Regional Action Plan on Marine litter, with a special focus on } \\
\text { plastic pollution. }\end{array}$ \\
\hline $\begin{array}{l}\text { Basel Convention on the Control of } \\
\text { Trans-boundary Movements of } \\
\text { Hazardous Wastes and Their Disposal }\end{array}$ & $\begin{array}{l}\text { Entered into force in 1992, the Convention is presently signed by } 187 \text { of the } 195 \text { countries in the World. Its main goal is to } \\
\text { reduce the production and toxicity of hazardous wastes, while promoting environmental management and enforcing restric } \\
\text { and highly regulated transboundary movements of hazardous wastes. Recently amended (BC-14/12) in May } 2019 \\
\text { enhancing the control of the transboundary movements of plastic waste (UNEP, 2019a). }\end{array}$ \\
\hline $\begin{array}{l}\text { Convention on Biological Diversity } \\
\text { (CBD). }\end{array}$ & $\begin{array}{l}\text { CBD entered into force in } 1993 \text { and signed by } 168 \text { countries, it is devoted to biological conservation. In } 2016 \text {, the } \\
\text { Conference of Parties urged members to implement within national jurisdiction measures to prevent and mitigate the } \\
\text { impacts of marine debris on marine and coastal biodiversity. }\end{array}$ \\
\hline $\begin{array}{l}\text { Food and Agriculture Organization } \\
\text { (FAO) of the UN's Code of Conduct for } \\
\text { Responsible Fisheries }\end{array}$ & $\begin{array}{l}\text { Adopted in 1995, this voluntary "code of conduct" seeks to promote long-term fisheries, setting the principles and } \\
\text { standards of behavior for the responsible practice of fisheries to ensure the conservation, management and development o } \\
\text { living aquatic resources. The Code includes the principle that fisheries should be conducted in manners that reduce the } \\
\text { generated waste and minimize the negative impacts on the environment. The voluntary nature of the accord has, however, } \\
\text { resulted in limited compliance by the signatory parties (Pitcher et al., 2006). }\end{array}$ \\
\hline $\begin{array}{l}\text { Strategic Approach to International } \\
\text { Chemicals Management (SAICM) }\end{array}$ & $\begin{array}{l}\text { Voluntary, SAICM was adopted in } 2006 \text { as a policy framework to promote chemical safety. Presently, SAICM is assessing } \\
\text { the possibility of considering plastics as materials of concern, as well as certain plastic additives, that constitute endocrine } \\
\text { disruptors (Ripley, 2019). }\end{array}$ \\
\hline The Honolulu Strategy & $\begin{array}{l}\text { One of the main outcomes of the Fifth International Marine Debris Conference, the Strategy consists of a "framework for a } \\
\text { comprehensive and global effort to reduce the ecological, human health, and economic impacts of marine debris globally" } \\
\text { (NOAA, 2011). The three main goals include the reduction of the amount of land- and ocean-generated waste, minimizatior } \\
\text { of their environmental impact and reduction of their accumulation on shorelines. As a framework document, the Strategy } \\
\text { does not supplant or supersede activities of national authorities, municipalities, industry, international organizations, or othe } \\
\text { stakeholders; rather, it calls for collaboration and cooperation between all agents based on the common goal and } \\
\text { developed and implemented tools. }\end{array}$ \\
\hline $\begin{array}{l}\text { Global Partnership of Marine Litter } \\
\text { (GPML) }\end{array}$ & $\begin{array}{l}\text { Under the auspices of UN Environment, GPML is a multi-stakeholder partnership launched at the UN Conference on } \\
\text { Sustainable Development Rio + 20. Its main goal is to "by 2025, prevent and significantly reduce marine pollution of all } \\
\text { kinds" (GPML, 2018) }\end{array}$ \\
\hline Regional Seas Conventions (RSC) & $\begin{array}{l}\text { Currently, } 18 \text { RSC exist. These serve as platforms for information exchange and international cooperation on pollution } \\
\text { issues. Seven are administered by UN Environment (Wider Caribbean, Northwest Pacific, Mediterranean, East Asian and } \\
\text { Caspian Seas, Eastern Africa and Western Africa) and an additional } 7 \text { are managed by other organizations [Red Sea and } \\
\text { Gulf of Aden, Black Sea, Northeast Pacific, ROPME Sea Area (Persian and Oman GulfS), South Asian Seas, Southeast } \\
\text { Pacific and Pacific] and } 4 \text { are independent regional seas (Antarctic, Arctic, Baltic and Northeast Atlantic) (Campbell et al., } \\
\text { 2017). }\end{array}$ \\
\hline
\end{tabular}

A brief description of each accord is included. The list does not purport to be exhaustive, but merely indicative of the numerous and varying regulatory initiatives in place.

Environment and Energy, specified that over $80 \%$ of the surveyed marine debris was comprised of plastic and that the reduction of the release of these materials into the environment, as well as the removal of the existing litter, is not only intended, but necessary (Tilley, 2017). However, perhaps the most emblematic and well recognized measure implemented by governments is the phasing out of lightweight plastic bags or the widely publicized bans on plastic straws (Mosquera, 2019), achieved through either the complete ban or charges on these products. Bangladesh and Denmark were among the first countries in the World to either introduce a charge for these products or a complete ban. In Portugal, for example, a plastic bag tax was implemented in February 2015. Results showed that, 2 years later, a $74 \%$ reduction of plastic bag consumption was observed, but accompanied by a simultaneous $61 \%$ increase of reusable plastic bags. Furthermore, the consumption of garbage bags also increased, by $12 \%$, due to the fact that, in the past, consumers used the previously untaxed carrier bags as garbage bags (Martinho et al., 2017).
When reviewing the existing public policies on plastic bags, Nielsen and colleagues concluded that $66 \%$ reduction in usage was observed in Denmark, and that this value could be as high as $90 \%$. Reduction on the use of plastic bags ranged between $75-90 \%$ in South Africa, Hong Kong, Belgium, and the United Kingdom, while in Botswana and China this reduction was of approximately $50 \%$ (Nielsen et al., 2019). In India, a ban on plastic bags has been enforced since 2016, with the goal of eliminating all disposable plastic products by 2022 and, in Costa Rica, all single-use plastics, including water bottles, bags and cups, are to be banned by 2021 (Vasilevskaia, 2018). However, perhaps the most evocative and dramatic example on this increasing action against single use carrier bags comes from Kenya, where the local government has not only implemented a total ban on plastic bags, but has also introduced of $\$ 40,000$ or imprisonment of up to 4 years for the production, sale or use of plastic bags (Harchekar and Kandalgaonkar, 2018), a measure that has also been implemented by Rwanda regarding polyethylene bags (Froidbise, 2015). However, particularly in the case of Kenya, this 
ban has created a black market for these products, and smuggling from the neighboring countries, especially across the Ugandan border along Lake Victoria, has threatened to undermine Kenya's ban on plastic bags (UNEnvironment, 2018). Literature detailing specific policies developed for other nations can be found elsewhere (Dauvergne, 2018; Lam et al., 2018; Schuyler et al., 2018) and a recent report by UNEP details the existing bans classified according to continent and country (UNEP, 2018).

Nearly 150 countries have implemented some form of legislation aimed at phasing-out the use of single plastics, and these are summarized in Figure 3, which does not illustrate measures not yet in effect.

Determining the actual, measurable effects in public awareness, and changes in behavior is challenging, and, although the strict enforcement of ban may ensure compliance, incremental approaches, such as the introduction of levies and charges, could, in the long term, yield more effective modifications in the motivation and attitudes of consumers, which is necessary for enduring changes in the consumption of single use plastics, such as carrier bags. Particularly in the case of emerging economies, while bans could temporarily alleviate some environmental issues, they fail to address the underlying problems, such as inadequate waste management infrastructures and management. Nevertheless, emerging economies, with little or no plastic production, and very limited recycling capabilities, have led the way an, in fact, proposed ambitions plans, at the international stage, to reduce the production and use of these plastics. For example, at the United Nations Environment Assembly (UNEA) in 2019, India piloted a resolution aimed at phasing out single-use plastics by 2025. The final March 15 th declaration removed the "decisive" intentions of the proposed measure and extended to timeline to 2030 , committing solely to a "reduction" by that time (UNEP, 2019b).

\section{LOCAL INITIATIVES}

At the local level, most actions developed have focused on larger plastics, and, in particular, plastic bags. These include efforts such as those developed, for example, in the city of Buenos Aires, Argentina, which has put in place a measure that allowed for supermarkets to charge for plastic bags, which, according to some estimates, lead to the reduction in their consumption of about 50\% (Télam, 2016). Following the apparent success of this enterprise, the city expanded this to a full ban on plastic bags. Other cities and provinces have also implemented bans on the distribution of plastic bags in supermarkets, a measure also enforced by approximately 80 municipalities in Chile. In the US, for example, San Francisco was one of the first cities to introduce plastic bag bans at groceries and supermarkets checkouts. Soon thereafter, bans on single-use plastics were enforced by over 135 state municipalities (Romer, 2007). However, for microplastics, there have been comparatively fewer initiatives developed at the local level. In the US, at the State level, Illinois developed proactive efforts that resulted in this state as the first to ban cosmetics containing microplastics. Soon, other states and counties approved legislation specifically aimed at phasing-out and/or completely eliminating synthetic microplastics, including the counties of Albany, Erie, Chautauqua, Cattaraugus and Suffolk, in the state of New York, and the states of Maryland, Indiana, Colorado, New Jersey, and Wisconsin (Xanthos and Walker, 2017). In Canada, the province of Ontario passed legislation banning the production of microplastics in 2015

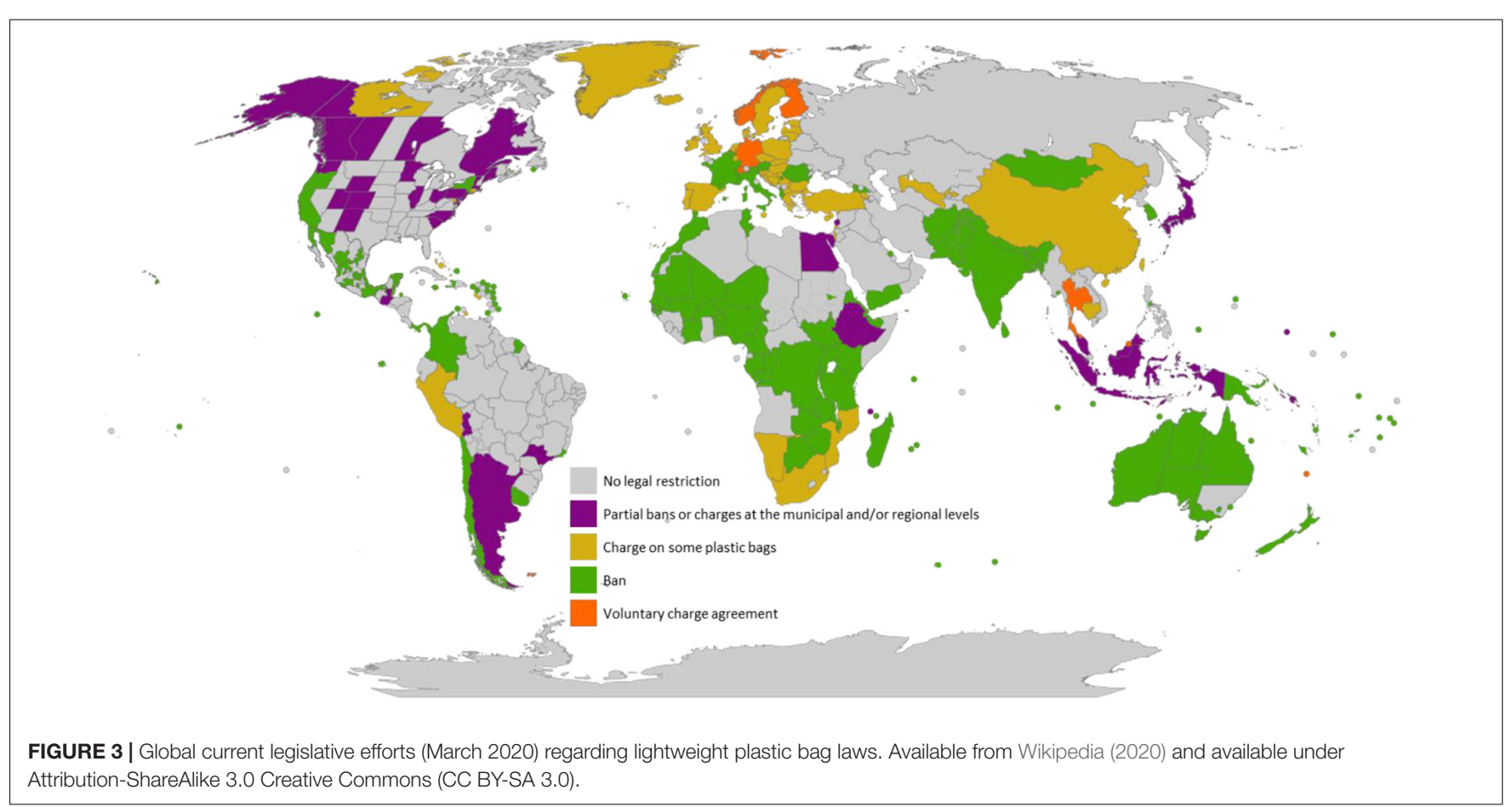


(Lalonde, 2015). Contrary to all these legislative efforts, in some states in the US, there have been some attempts at classifying the current bans as illegal, effectively imposing a "ban on bans." In fact, some legislators in at least 17 states make such a claim and four states created preemptions during 2019, with two narrowly failing in South Carolina and Alabama. Presently, eight other states (Texas, Colorado, Arizona, Idaho, Minnesota, Michigan, Wisconsin, and Florida) are evaluating the implementation of preemption measures making it illegal to ban single-use plastics (Gibbens, 2019). Simultaneously, legislators defending these bans have begun to draft anti-preemption bills, putting to a vote what can best be described as a "ban on ban of bans." Presently, however, no such bill has significantly progressed, which may pave the way to significant roll-backs and regression of the policies so far imposed.

Though sparse, these local efforts, when combined with those developed at the national, regional and national levels are encouraging policies that may have beneficial environmental impacts. However, the current phasing-out period or recent implementation of these initiatives render their efficiency uncertain, and some doubts remain on how such bans will be implemented and enforced.

\section{REGULATORY INSTRUMENTS CORRELATION AND EFFICACY}

All regulatory instruments devised, whether at the local, regional or international level, address pollution through one or more venues of intervention, which, broadly, may be classified as (Chen, 2015):

(1) Preventive - focuses on the $3 \mathrm{R}$ rule: reuse, reduction (at sources) and recycling, as well as on multiple land-based management actions;

(2) Removal - debris monitoring and clean-up initiatives;

(3) Mitigation - litter disposal and development of discharge regulations;

(4) Educational - covers awareness campaigns and economic/incentive approaches.

However, such strategies are often developed within specific frameworks and/or by certain organizations or groups with limited coordination between all stake holders. For example, when social movements pushed for the ban of microbeads in the US, companies such as Procter \& Gamble and Johnson \& Johnson lobbied for legislation that allowed for the inclusion of "biodegradable" microbeads (Dauvergne, 2018). Nonetheless, such "biodegradable loophole" would fail to consider that not only there is an ongoing scientific debate regarding the supposed biodegradability of such materials (Van den Oever et al., 2017), thus undermining the applicability of the ban; furthermore, these biodegradable microbeads would still pose a severe risk to the environment owing to their low degree of biodegradation in deep, cold, and dark waters and the retained ability to leach associated toxins and chemicals. A profound discussion and collaboration between all interested parties could have perhaps lead to a more productive and timely solution, as the proposed use of soluble polyhydroxyalkanoate (PHA) microbeads (Bhattacharya, 2016), or, more recently, the use of salt, jojoba (Simmondsia chinensis) beads, ground coffee and diatomaceous earth (Mastrup et al., 2018) in some exfoliating products. This stems from the apparent lack of integration and interaction between the policies developed at the different levels of intervention, often applied in isolation, as depicted in Figure 4A. A more desirable approach is depicted in Figure 4B, where the focus of the applied regulatory tools and instruments percolate from international to regional, national and local levels. This could help in filling some of the existing regulatory and legislative gaps that exist. If addressed, it may actively contribute to the desired reduction of the prevalence of plastic, in particular, and litter, in general, in the environment. Such gaps include regulatory insufficiency on the scope regarding the existing main sources of plastic pollution (Gold et al., 2014), which vary greatly at the levels of intervention, the present lack of implementation and enforcement of existing regulations and management actions (Chen, 2015), poor international cooperation and insufficient participation of states in regional initiatives (Interwies et al., 2013) and, perhaps more limiting in the development of these legal tools, the current lack of sufficient scientifically gathered data on the prevalence of plastic debris in the environment (da Costa et al., 2017). But there are also inherent national and regional challenges, owing to societal changes, namely, rapid economic growth, urbanization, and changing production and consumption behaviors, that may affect the efficiency of efforts to curtail the prevalence of these materials (Akenji et al., 2020). Moreover, in spite of the implementation of bans, for example, these have sometimes been done with little to no consultation and, in some cases, without national campaigns and/or limited notification (Adam et al., 2020).

\section{THE ROLE OF THE MEDIA AND SOCIAL NETWORKS}

In spite of all the aforementioned initiatives, plastic pollution levels continue to increase, and, concomitantly, so has the awareness of not only the scientific community, but of the general public as well. This mindfulness has been propelled by both the "traditional" and "social media," which plays a growing role in everyday life. In the past decade, information technology has fundamentally changed communication, and, presently, social media platforms have been firmly established as immediate and effective forms of sharing information. In fact, this effectiveness has been recognized by regulators, such as capital market regulators, as viable disclosure channels for key information, as evidenced by the decision by SEC (U.S. Securities and Exchange Commission) to allow companies to announce important information in compliance with Regulation Fair Disclosure (Jung et al., 2017). Similarly, the World Health Organization (WHO) has developed Social media toolkits for the release of the WHO reports, such as the "Air Pollution and Child Death" (World Health Organization [WHO], 2018). As a consequence, the public has become more cognizant of the current levels of plastic contamination and of their ultimate consequences, a consciousness that has been continuously 

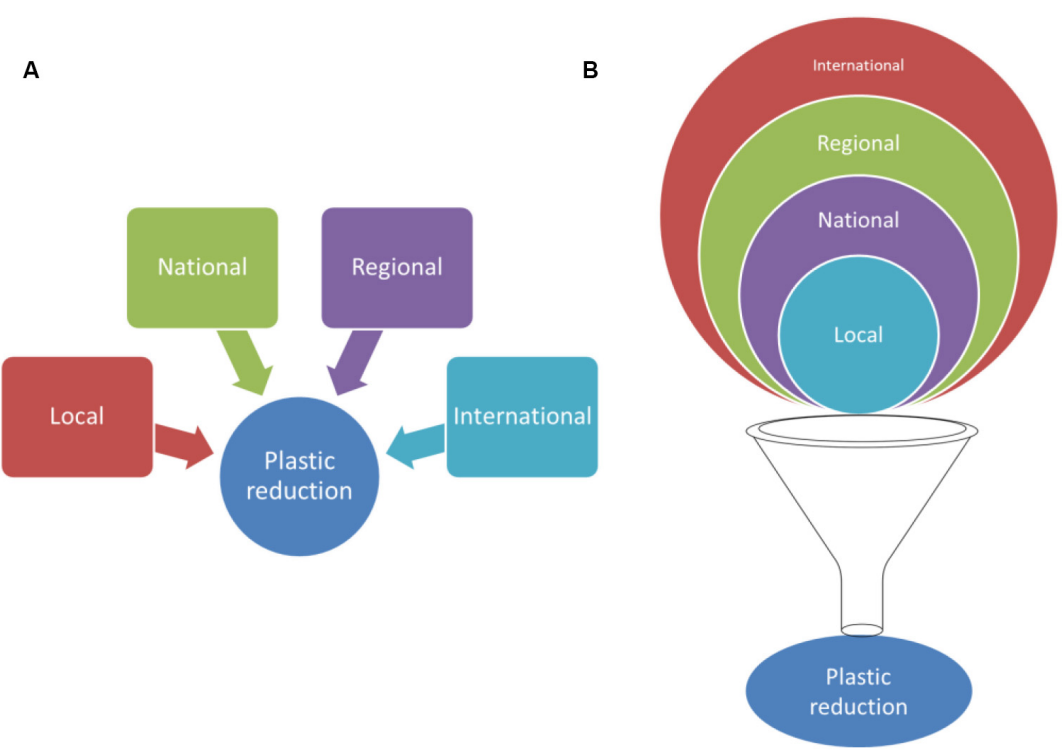

FIGURE 4 | In (A), how, currently, the different levels of regulatory instruments are applied. In (B), how, ideally, such instruments should interact and correlate, effectively constituting the framework of a global approach toward the reduction of plastic waste in the environment.

sustained by continual information dissemination of the hazards these materials pose to the environment (e.g., Carrington, 2016, 2018; Rodrigues and Firmino, 2017; Gosling, 2018). Hashtags are metadata tags that are used on social networks services that allow users to apply user-generated dynamic tagging that facilitates finding messages with specific content or within a specific theme. In the recent past, these tags have been used to popularize different challenges that rapidly reached the status of viral, i.e., that circulated vary fast and widely on the Internet (Baghel et al., 2018). Environmentally, this impact is reflected, for example, in initiatives such as the so-called "cleanup challenge," circulated online through the hashtags "\#cleanup" and/or "\#trashtag." This challenge, classified as viral, encourages people to clean up litter and participation requires simply the search for a litter-filled area or overflowing trashcan, cleaning, and subsequently sharing "before" and "after" photos online using the aforementioned hashtags. This challenge has been taking place for some years and, according to HashtagsForLikes, a website dedicated to measuring exposure for content and social media profiles, these hashtags are "long-lived," with a total of over fifty thousand unique online posts, on one social media platform alone (Hashtagsforlikes, 2019). As of January 2019, brand24.com estimates a 2.2 million regarding social media reach, based on number of authors, respective followers and average visibility percentage (Brand24, 2019). On a regulatory level, social media has reportedly have shown some traction for tackling air pollution in China. Following the initiative of the Embassy of the United States in Beijing to publish the results of its air quality sensor in 2008, Chinese microbloggers focused their attention on the subject of air pollution and, in 2012, the Chinese government introduced new air quality standards. This was hailed as a victory for these online activists, and broadly considered a significant step toward the emergence of social media as a democratizing force
(Kay et al., 2015). Complementarily, web-based and smartphone technologies allow not only to disseminate, but also to gather information. Hence, such technologies can be used, for example, to reach wider numbers of participants in studies focused on assessing pollution, but also the consequences, on a physical and/or psychological level (Zhang et al., 2014a), although such approaches remain largely underexplored and have been mostly used under detailed conditions, such as specific crises (Zhang et al., 2014b). Ultimately, although such online movements may have helped inspiring people of all ages, but particularly young people to save the natural world, the question remains: can social media-based initiatives solve plastic pollution? No, but they can propel much needed changes that are the core of plastic pollution, and these are not at the end of the life cycle of these products, but rather at the beginning. In other words, these movements that are gaining momentum could drive the transition from a plastic-based economy toward an alternative one.

\section{THE ROAD AHEAD}

Notwithstanding the growing number of regulatory and legislative initiatives, as well as the willingness to address the already mentioned existing gaps, mostly propelled by an increasing awareness of the general public regarding the risks microplastics pose to the environment, and, ultimately, health, the development of regulatory instruments developed specifically aimed at curtailing the prevalence of these materials is significantly hindered by the lag time between reporting of research results and the subsequent implementation of evidencebased strategies, commonly defined as the "enlightenment function" (da Costa, 2018). Additionally, policies and research are developed within different operating settings, which are 
frequently delimited by diverse professional resources, culture and timeframes. Consequently, it becomes necessary to more proactively intertwine the different stakeholders toward the development of evidence-based approaches that are not the end-point of a linear method, but rather a stage of a more circular, dynamic and integrative process, often described as "knowledge brokering" (van Kammen et al., 2006) that may lead to continuous improvements - tweaks - aimed at better achieving the proposed goals. The brokering of knowledge may be accomplished by actively fostering communication between the involved parties, by setting common goals and agendas, by organizing joint forums for researchers and policy makers alike and by establishing the current and future informational needs. In fact, in this regard, there is much that remains unknown. Recently, SAPEA (Science Advice for Policy by European Academies) published a Report reviewing the current scientifically available evidence on the issue of microplastics with the aim of informing the European Union Commission's Group of Chief Scientific Advisors (SAPEA, 2019). The conclusions detail the mix of consensus on the pollution and impacts of microplastics and how, in spite of the informed extrapolation, significant speculation and many unknowns remain, reflecting "both the immaturity of the field and its intrinsic complexity" (SAPEA, 2019). The overall scientific conclusion does point toward the (temporary) conclusion that microplastic pollution does not constitute a widespread risk. However, if uncontrolled, microplastic pollution, combined with its long-term persistence and irreversibility, will lead to effect concentration thresholds that will effectively constitute a widespread risk within a century. It is therefore not surprising that the report exhorts the development of "reasonable and proportional measures" aimed at preventing the direct release of microplastics into the environment and their formation from the fragmentation of larger plastics. Policy tools, including bans and taxation, are just some of the solutions required to address this growing global concern. In the long-term, education, outreach and awareness initiatives regarding the issue of plastic pollution and microplastics, may represent the best strategies and approaches. This can be achieved by actively developing and implementing education and outreach programs to modify behavior (Kershaw et al., 2011). Ocean, pollution, and waste management education in schools could prove to be of great value, particularly, in the long term, as education and behavioral changes of children represent an important source of social influence among their parents, peers and local communities (Hartley et al., 2015).

Another important step is that under consideration by the European Chemicals Agency (ECHA). Currently under "opinion development," a proposal has been submitted considering restriction options under REACH (Registration, Evaluation, Authorization and Restriction of Chemicals) to address the potential risks of microplastics. The proposed restriction scenario aims at restricting the use of intentionally added microplastics to consumer or professional use products of any kind (ECHA, 2019). Furthermore, the considered working definition was deemed to be applicable to all polymers, and not solely to thermosets and thermoplastics - i.e., plastics that are and are not irreversibly molded after the initial forming, respectively (Rennie,
1999). The document focuses on numerous fields of applications, including agriculture, cosmetics, paints and coatings, as well as medical/pharmaceutical applications, detergents and the oil and gas sectors. Although only aimed at intentionally added microplastics, if entered into effect, this restriction will greatly contribute to the reduction of primary microplastics into the environment.

For secondary microplastics, reduction strategies are essential tools to reduce the emission of the larger plastic materials from which these smaller particles derive. Consistent and complimentary measures must be continuously implemented to help mitigate plastic pollution.

\section{CONCLUSION}

There has been a steady increase in awareness of the environmental, economic, social, public safety and individual health risks posed by (micro)plastic pollution. This has led to the development of numerous and diverse sets of regulatory tools at local, national, regional, and international levels. Whether voluntary or compulsory, bottom-up governance, whilst highly fragmented, has paved the way and made clear advances in reducing some forms of plastic pollution at the global scale. Internationally, the developed efforts vary in scope and range, focusing on the manufacture, commercialization and use of microplastics, while, at the national and regional levels, most initiatives endeavor to curtail plastic pollution by imposing either levies or bans, whether full or partial. Yet, such instruments have insofar been deemed insufficient. Multiple jurisdictions, producers and retailers lag behind and the industry continues to actively fight some of the legislative propositions. At the fundamental research level, there is also the need to gather more data regarding the real prevalence and effects of these materials in both biota and the environment as only such a detailed knowledge will allow the suitable development of adequate and efficient regulations. Bans, corporate commitments and bioplastics will not curtail the current global plastic pollution problem. Ultimately, the best approach for dealing with this issue will include a multitude of multi-tiered approaches. These will inevitably include bottom-up governance, local, national, regional and international hard and soft laws. Better waste management, as well as better infrastructures, are needed. Corporations will have to reconsider the design of their products based on the implementation of a closed, circular economy, considering all stages of their products, from "cradle to the grave." Consumers will also have to adjust their behaviors, and, together with manufacturers, shift toward a culture of reduction, reuse, and recycle. Significant strides will then be possible for the reduction of plastic entering the environment, though the question remains: will that have been enough and on time?

\section{AUTHOR CONTRIBUTIONS}

JC researched the subject and prepared the document, based on the idea put forth by AD and TR-S. CM and MC supported 
the preparation of the manuscript. All the authors discussed the results and contributed to the final manuscript.

\section{FUNDING}

Thanks are due to FCT/MCTES for the financial support (UIDP/50017/2020 and UIDB/50017/2020), through national funds. This work was funded by national funds (OE), through

\section{REFERENCES}

Adam, I., Walker, T. R., Bezerra, J. C., and Clayton, A. (2020). Policies to reduce single-use plastic marine pollution in West Africa. Mar. Policy 116:103928. doi: 10.1016/j.marpol.2020.103928

AISE, CIRFS, EOG, EURATEX, and FESI (2017). Cross Industry Agreement for the Prevention Of Microplastic Release Into The Aquatic Environment During The Washing Of Synthetic Textiles. Brussels: AIES.

Akenji, L., Bengtsson, M., Hotta, Y., Kato, M., and Hengesbaugh, M. (2020). "Chapter 21 - Policy responses to plastic pollution in Asia: summary of a regional gap analysis1," in Plastic Waste and Recycling, ed. T. M. Letcher (Cambridge, MA: Academic Press), 531-567. doi: 10.1016/b978-0-12-8178805.00021-9

Baghel, N., Kumar, Y., Nanda, P., Shah, R. R., Mahata, D., and Zimmermann, R. (2018). Kiki kills: identifying dangerous challenge videos from social media. arXiv [Preprint]. Available online at: https://arxiv.org/abs/1812.00399 (accessed May 15,2020$)$.

Bateman, S. (2007). UNCLOS and its limitations as the foundation for a regional maritime security regime. Korea. J. Defense Anal. 19, 27-56. doi: 10.1080/ 10163270709464140

Beament, M. (2018). McDonalds to Ban Plastic Straws In All Of Its Restaurants in UK and Ireland. London: Independent Print Limited.

Bellas, J. (2014). The implementation of the marine strategy framework directive: shortcomings and limitations from the spanish point of view. Mar. Policy 50, 10-17. doi: 10.1016/j.marpol.2014.05.004

Bhattacharya, P. (2016). A review on the impacts of microplastic beads used in cosmetics. Acta Biomed. Sci. 3:4.

Brand24. (2019). Media Monitoring Made Easy. Available online at: https:// brand24.com/ (accessed September 30, 2019).

Butler, S. (2018). Ikea Commits To Phase Out Single-Use Plastic Products By 2020 in the Guardian. London: Guardian Media Group.

CAMLR (2018). Report of the 37th Meeting of the Scientific Commitee. Hobart: CAMLR.

Campbell, D., Hasegawa, K., Long, W. L., Mongensen, C., Leone, G., RodriguezLucas, L., et al. (2017). Regional Seas Programmes Covering Areas Beyond National Jurisdictions, In Regional Seas Reports And Studies No.202. Nairobi: UN.

Carrington, D. (2016). Microplastics May Be Contaminating the Air We Breathe. London: Guardian News and Media.

Carrington, D. (2018). Microplastic Pollution In Oceans Is Far Worse Than Feared, Say Scientists. London: Guardian Media Group.

Chen, C.-L. (2015). "Regulation and management of marine litter," in Marine Anthropogenic Litter, eds M. Bergmann, L. Gutow, and M. Klages (Cham: Springer), 395-428. doi: 10.1007/978-3-319-16510-3_15

Corbin, C., Wedemier-Graham, S., and Franc, E. (2014). Regional Action Plan on Marine Litter Management (RAPMaLi) for the Wider Caribbean Region. Nairobi: UNEP.

Crawford, C. B., and Quinn, B. (2017). 3 - Plastic production, waste and legislation. Microplast. Pollut. 2017, 39-56. doi: 10.1016/b978-0-12-809406-8. 00003-7

da Costa, J. P. (2018). Micro-and nanoplastics in the environment: research and policymaking. Curr. Opin. Environ. Sci. Health 1, 12-16. doi: 10.1016/j.coesh. 2017.11.002

da Costa, J. P., Duarte, A. C., and Rocha-Santos, T. A. P. (2017). "Chapter 1 - microplastics - occurrence, fate and behaviour in the environment," in
FCT - Fundação para a Ciência e a Tecnologia, I.P., in the scope of the framework contract foreseen in the numbers 4 , 5 , and 6 of the article 23, of the Decree-Law 57/2016, of August 29, changed by Law 57/2017, of July 19th. This work is a contribution to project MicroPlasTox, with the reference POCI-01-0145-FEDER-028740, funded by FEDER, through COMPETE2020 - Programa Operacional Competitividade e Internacionalização (POCI), and by national funds (OE), through FCT/MCTES.

Comprehensive Analytical Chemistry, eds A. P. R.-S. Teresa and C. D. Armando (Amsterdam: Elsevier), 1-24. doi: 10.1016/bs.coac.2016.10.004

Dauvergne, P. (2018). The power of environmental norms: marine plastic pollution and the politics of microbeads. Environ. Polit. 27, 579-597. doi: 10.1080/ 09644016.2018.1449090

Dewey, J. T. (2018). Rethinking MARPOL enforcement. Coast guard journal of safety \& security at Sea. Proc. Mar. Saf. Secur. Council 75, 54-57.

ECHA (2019). Restricting the Use Of Intentionally Added Microplastic Particles To Consumer Or Professional Use Products Of Any Kind. Helsinki: European Chemicals Agency.

Ehlers, P. (1993). The helsinki convention, 1992-improving the baltic sea environment. Int. J. Mar. Coast. L. 8:191. doi: 10.1163/157180893x00017

Eschener, K. (2019). Unilever's Plan To Stop Massive Plastic Pollution From Destroying The Oceans. Englewood Cliffs, NJ: CNBC.

ESPO (ed.) (2018). Position of the European Sea Ports Organisation on the Commission's proposal on Port Reception Facilities. Brussels: ESPO.

EuropeanParliament (ed.) (2000a). Directive 2000/59/EC, in 2000/59/EC. Strasbourg: EU.

EuropeanParliament (ed.) (2000b). Directive 2000/60/EC, in 2000/60/EC. Strasbourg: EuropeanParliament.

EuropeanParliament (ed.) (2004). Directive 2004/12/EC, in 2004/12/EC. Strasbourg: EU.

EuropeanParliament (ed.) (2008). Directive 2008/56/EC, in 2008/56/EC. Strasbourg: European Union.

EuropeanParliament (ed.) (2017). Commission Decision Laying Down Criteria And Methodological Standards On Good Environmental Status Of Marine Waters And Specifications And Standardised Methods For Monitoring And Assessment, And Repealing Decision 2010/477/EU, in 2017/848. Brussels: EuropeanParliament.

EuropeanParliament (ed.) (2018). A European Strategy for Plastics in a Circular Economy. Brussels: EU.

EuropeanParliament (ed.) (2019a). Directive (EU) 2019/904 of the European Parliament and of the Council of 5 June 2019 on the Reduction of the Impact Of Certain Plastic Products On The Environment, in PE/11/2019/REV/1. Brussels: European Union.

EuropeanParliament (ed.) (2019b). Directive on Port Reception Facilities For The Delivery Of Waste From Ships, Amending Directive 2010/65/EU and repealing Directive 2000/59/EC in PE/85/2018/REV/1. Strasbourg: EU.

FAO (2013). Regional Fishery Bodies Summary Descriptions. Commission for the Conservation of Antarctic Marine Living Resources (CCAMLR). Fishery Governance Fact Sheets. Rome: FAO.

Froidbise, A. (2015). Behind the Scenes Of The Plastic Bag Ban In Rwanda: Connections To Culture, Power And Sustainability. Cham: Springer.

G20. (2017). G20 Action Plan on Marine Litter. Hamburg: G20 Foundation.

G7. (2018). Statement on the issue of Marine Litter for the G7 Environment Ministers Meeting 2018. Available online at: https://fslci.org/g7-marine-litter-statement/ (accessed May 25, 2020).

Gagain, M. (2012). Climate change, sea level rise, and artificial islands: saving the Maldives' statehood and maritime claims through the constitution of the oceans. Colo. J. Int. Environ. L. Pol. $23: 77$.

Gago, J., Galgani, F., Maes, T., and Thompson, R. C. (2016). Microplastics in seawater: recommendations from the marine strategy framework directive implementation process. Front. Mar. Sci. 3:219. doi: 10.3389/fmars.2016.00219

Gibbens, S. (2019). See the Complicated Landscape Of Plastic Bans in the U.S. Environment. London: U.S. Environment. 
Gjerde, K. M., Currie, D., Wowk, K., and Sack, K. (2013). Ocean in peril: reforming the management of global ocean living resources in areas beyond national jurisdiction. Mar. Pollut. Bull. 74, 540-551. doi: 10.1016/j.marpolbul.2013.07. 037

Gold, M., Mika, K., Horowitz, C., Herzog, M., and Leitner, L. (2014). Stemming the tide of plastic marine litter: a global action agenda. Tulane Environ. Law J. 27, 165-203.

Gosling, M. (2018). Drinking Water Contaminated With Micro Plastic Pollution In Gauteng. Cape Town: news24.

GPML (2018). Global Partnership on Marine Litter (GPML) - Purpose, function and organization. New York, NY: UN.

Groh, K. J., Backhaus, T., Carney-Almroth, B., Geueke, B., Inostroza, P. A., Lennquist, A., et al. (2019). Overview of known plastic packaging-associated chemicals and their hazards. Sci. Total Environ. 651, 3253-3268. doi: 10.1016/ j.scitotenv.2018.10.015

Harchekar, J. S., and Kandalgaonkar, S. (2018). Ban on plastic! a blessing or a curse. Intern. J. Eng. Manag. Res. 8, 77-79. doi: 10.31033/ijemr.8.5.9

Hartley, B. L., Thompson, R. C., and Pahl, S. (2015). Marine litter education boosts children's understanding and self-reported actions. Mar. Pollut. Bull. 90, 209-217. doi: 10.1016/j.marpolbul.2014.10.049

Hashtagsforlikes (2019). Most Popular Hashtags for \#Cleanup on Instagram. Available online at: https://www.hashtagsforlikes.co/hashtag/cleanup (accessed September 30, 2019).

HELCOM (2019). HELCOM - Publications. Available online at: http://www. helcom.fi/helcom-at-work/publications (accessed July 24, 2019).

Huang, J. J., and Hu, J. (2018). Can free trade agreements enhance MARPOL 73/78 compliance? Tulane Mar. L. J. 43, 59-91.

IMO (1988). MARPOL, in Annex V-Prevention of Pollution by Garbage from Ships. London: International Maritime Organization.

IMO (1996). 1996 Protocol to the Convention of the Prevention of Marine Pollution by Dumping Wastes and Other Matter, 1972. London: IMO.

Interwies, E., Görlitz, S., Stöfen, A., Cools, J., van Breusegem, W., Werner, S., et al. (2013). Issue Paper to the International Conference on Prevention and Management of Marine Litter in European Sea. Nairobi: UNEP.

Jung, M. J., Naughton, J. P., Tahoun, A., and Wang, C. (2017). Do firms strategically disseminate? Evidence from corporate use of social media. Acc. Rev. 93, 225252. doi: $10.2308 /$ accr- 51906

Kay, S., Zhao, B., and Sui, D. (2015). Can social media clear the air? a case study of the air pollution problem in chinese cities. Prof. Geogr. 67, 351-363. doi: 10.1080/00330124.2014.970838

Kershaw, P., Katsuhiko, S., Lee, S., and Woodring, D. (2011). Plastic Debris In The Ocean. Nairobi: United Nations Environment Programme.

Kim, S. K. (2015). Marine pollution response in Northeast Asia and the NOWPAP Regime. Ocean Dev. Intern. L. 46, 17-32. doi: 10.1080/00908320.2014. 929470

Kimball, L. A. (2005). The international legal regime of the high seas and the seabed beyond the limits of national jurisdiction and options for cooperation for the establishment of Marine Protected Areas (MPAs) in marine areas beyond the limits of national jurisdiction. Secretariat of the Convention on Biological Diversity, Montreal, Technical Series no. 19, 64.

Lalonde, M. F. (2015). Microbead Elimination and Monitoring Act, in Bill 752015. Ontario: OLA

Lam, C.-S., Ramanathan, S., Carbery, M., Gray, K., Vanka, K. S., Maurin, C., et al. (2018). A comprehensive analysis of plastics and microplastic legislation worldwide. Water Air Soil Pollut. 229:345.

Lewis, S. L., and Maslin, M. A. (2015). Defining the anthropocene. Nature 519:171. doi: $10.1038 /$ nature 14258

Lithner, D., Larsson, A., and Dave, G. (2011). Environmental and health hazard ranking and assessment of plastic polymers based on chemical composition. Sci. Total Environ. 409, 3309-3324. doi: 10.1016/j.scitotenv.2011.04.038

Martinho, G., Balaia, N., and Pires, A. (2017). The portuguese plastic carrier bag tax: the effects on consumers' behavior. Waste Manag. 61, 3-12. doi: 10.1016/j. wasman.2017.01.023

Mastrup, N. S., Pearce, J. R., Palm, S. K., Jiang, C., Wang, Q., Humphreys, B. S., et al. (2018). Non-Respirable Powdered Diatomaceous Earth Products. U.S. Patent Application No. 15/524,974, 2018.

Mosquera, M. R. (2019). Banning plastic straws: the beginning of the war against plastics. Earth Jurisprud. Environ. Just J. 9:5.
Neretin, L. (2018). UNEP Efforts to Combat Marine Litter. New York, NY: UN.

Nielsen, T. D., Holmberg, K., and Stripple, J. (2019). Need a bag? A review of public policies on plastic carrier bags - where, how and to what effect? Waste Manag. 87, 428-440. doi: 10.1016/j.wasman.2019.02.025

NOAA (2011). The Honolulu Strategy: A Global Framework for Prevention and Management of Marine Debris. Honolulu.

NOAA (ed.) (2015). Microplastics One Pager. Silver Spring, MD: NOAA.

O'Halloran, M. (2017). Government Drops Opposition To Bill Banning Microplastics. Dublin: Irish Times.

OSPAR (ed.) (2010). Guideline for Monitoring Marine Litter on the Beaches in the OSPAR Maritime Area. Los Angeles, CA: OSAPR.

Pettipas, S., Bernier, M., and Walker, T. R. (2016). A Canadian policy framework to mitigate plastic marine pollution. Mar. Policy 68, 117-122. doi: 10.1016/j. marpol.2016.02.025

Pitcher, T., Kalikoski, D., and Pramod, G. (2006). Evaluations of Compliance With the FAO (UN) Code of Conduct for Responsible Fisheries. Vancouver: University of British Columbia.

PlasticsEurope (ed.) (2019). Plastics - the Facts 2019, PlasticsEurope and EuPC. Brussels: Plastics Europe.

Rennie, A. R. (1999). “Thermoplastics and thermosets", in Mechanical Properties and Testing of Polymers: An A-Z Reference, ed. G. M. Swallowe (Dordrecht: Springer), 248-248.

Ripley, K. (2019). SAICM-IP-3: formation of a post-2020 platform begins. Environ Pol. L. 49, 328-338. doi: 10.3233/epl-190184

Rochette, J., Unger, S., Herr, D., Johnson, D., Nakamura, T., Packeiser, T., et al. (2014). The regional approach to the conservation and sustainable use of marine biodiversity in areas beyond national jurisdiction. Mar. Policy 49, 109-117. doi: 10.1016/j.marpol.2014.02.005

Rodrigues, C., and Firmino, T. (2017). Um Oceano De Plástico In Público. Maia: Unipress.

Romer, J. R. (2007). The evolution of San Francisco's plastic-bag ban. Gold. Gate Univ. Environ. L. J. 1:439.

ROPME (1979). Kuwait Regional Convention for Cooperation on the Protection of the Marine Environment from Pollution. Kuwait: ROPME.

Ryan, P. G., Moore, C. J., van Franeker, J. A., and Moloney, C. L. (2009). Monitoring the abundance of plastic debris in the marine environment. Philos. Trans. R. Soc. B Biol. Sci. 364, 1999-2012.

SAPEA (2019). A Scientific Perspective On Microplastics In Nature And Society. New York, NY: SAPEA.

Schlanger, Z. (2018). Plastic Production Has Skyrocketed Since The 1950s. Available online at: https://www.theatlas.com/charts/BkAVFsjrb (accessed July 10, 2019).

Schuyler, Q., Hardesty, B. D., Lawson, T. J., Opie, K., and Wilcox, C. (2018). Economic incentives reduce plastic inputs to the ocean. Mar. Policy 96, 250255. doi: 10.1016/j.marpol.2018.02.009

ScottishGovernment (2013). Marine Litter Strategy, National Litter Strategy: Strategic Environmental Assessment Environmental Report. Scotland: ScottishGovernment.

SREP (2016). Cleaner Pacific 2025 - Pacific Regional Waste and Pollution Management Strategy 2016-2025. Samoa: SREP.

Tagg, A. S., and Labrenz, M. (2018). Closing Microplastic Pathways Before They Open: A Model Approach. Washington, DC: ACS Publications.

Télam (2016). El Gobierno Porteño Anunció Que Desde 2017 Se Prohibirán Bolsas Plásticas En Los Súper. Buenos Aires: Télam.

Tilley, K. (2017). Australian Draft Plan Aims To Reduce Marine Debris. Available online at: http://www.plasticsnews.com/article/20170410/NEWS/170419991/ australian-draft-plan-aims-to-reduce-marine-debris (accessed cited July 27, 2017).

UNEnvironment (2018). How Smuggling Threatens To Undermine Kenya's Plastic Bag Ban. Available online at: https://www.unenvironment.org/news-andstories/story/how-smuggling-threatens-undermine-kenyas-plastic-bag-ban (accessed September 23, 2019).

UNEP (ed.) (2019a). Addressing Single-Use Plastic Products Pollution in UNEP/EA.4/L.10. Nairobi: UNEP.

UNEP (2019b). Amendments to Annexes II, VIII and IX to the Basel Convention, in $B C-14 / 12$. Nairobi: U. Nations.

UNEP (ed.) (2017). Draft Resolution On Marine Litter And Microplastics in UNEP/EA.3/L.20, U.N.E. Assembly. Nairobi: UNEP. 
UNEP (ed.) (2018). Single-Use Plastics: A Roadmap for Sustainability. Nairobi: UNEP.

UNEP/NOAA (2011). The Honolulu Strategy: A Global Framework For Prevention And Management Of Marine Debris. Nairobi: UNEP.

UNEP-GPA (2018). Regional Action - East Asian Seas. Available online at: http: //marine-litter.gpa.unep.org/framework/region-15-next.htm (accessed July 24, 2019).

United Nations (2020). United Nations Decade of Ocean Science for Sustainable Development. Available online at: https://www.oceandecade.org/ (accessed May $25,2020)$.

United Nations (1982). United Nations Convention on the Law of the Sea, in 31363. Jamaica: UN General Assembly.

USCongress (ed.) (2015). Microbead-Free Waters Act of 2015, in H.R. 1321. Washington, DC: USC.

Van den Oever, M., Molenveld, K., van der Zee, M., Bos, H., et al. (2017). Bio-Based And Biodegradable Plastics: Facts And Figures: Focus On Food Packaging In the Netherlands. Wageningen: Wageningen Food \& Biobased Research.

van Kammen, J., de Savigny, D., and Sewankambo, N. (2006). Using knowledge brokering to promote evidence-based policy-making: the need for support structures. Bull. World Health Organ. 84, 608-612. doi: 10.2471/blt.05. 028308

Vasilevskaia, D. (2018). Marine Plastic Pollution: Can Law Help?. Available online at: https://legal-dialogue.org/marine-plastic-pollution-can-law-help (accessed July 10, 2019).

Vermaire, J. C., Pomeroy, C., Herczegh, S. M., Haggart, O., and Murphy, M. (2017). Microplastic abundance and distribution in the open water and sediment of the Ottawa River, Canada, and its tributaries. Facets 2, 301-314. doi: 10.1139/ facets-2016-0070

Vince, J., and Hardesty, B. D. (2018). Governance solutions to the tragedy of the commons that marine plastics have become. Front. Mar. Sci. 5:214. doi: $10.3389 /$ fmars.2016.00214
Waller, C. L., Griffiths, H. J., Waluda, C. M., Thorpe, S. E., Loaiza, I., Moreno, B., et al. (2017). Microplastics in the Antarctic marine system: An emerging area of research. Sci. Total Environ. 598, 220-227. doi: 10.1016/j.scitotenv.2017.03.283

WEF (ed.) (2016). The New Plastics Economy - Rethinking the Future Of Plastics. Cologny: World Economic Forum.

World Health Organization [WHO] (ed.) (2018). WHO Social Media Toolkit For Air Pollution And Child Health: Prescribing Clean Air Launch. Geneva: WHO.

Wikipedia (2020). Phase-out of Lightweight Plastic Bags. Available online at: https: //en.wikipedia.org/wiki/Phase-out_of_lightweight_plastic_bags (accessed July 22, 2019).

Xanthos, D., and Walker, T. R. (2017). International policies to reduce plastic marine pollution from single-use plastics (plastic bags and microbeads): a review. Mar. Pollut. Bull. 118, 17-26. doi: 10.1016/j.marpolbul.2017.02.048

Zhang, M. W., Ho, C., Fang, P., Lu, Y., Ho, R. C., et al. (2014a). Usage of social media and smartphone application in assessment of physical and psychological well-being of individuals in times of a major air pollution crisis. JMIR Mhealth Uhealth 2:e16. doi: 10.2196/mhealth.2827

Zhang, M. W., Ho, C. S., Fang, P., Lu, Y., and Ho, R. C. (2014b). Methodology of developing a smartphone application for crisis research and its clinical application. Technol. Health Care 22, 547-559. doi: 10.3233/thc-140819

Conflict of Interest: The authors declare that the research was conducted in the absence of any commercial or financial relationships that could be construed as a potential conflict of interest.

Copyright (C) 2020 da Costa, Mouneyrac, Costa, Duarte and Rocha-Santos. This is an open-access article distributed under the terms of the Creative Commons Attribution License (CC BY). The use, distribution or reproduction in other forums is permitted, provided the original author(s) and the copyright owner(s) are credited and that the original publication in this journal is cited, in accordance with accepted academic practice. No use, distribution or reproduction is permitted which does not comply with these terms. 